\title{
From headwaters to estuary: distribution, sources, and ecological risk of polycyclic aromatic hydrocarbons in an intensively human-impacted river, China
}

\author{
Yanan $\mathrm{Li}^{1,2} \cdot$ Xiaomei Zhen ${ }^{1,2,3} \cdot \operatorname{Lin~Liu}^{1,2,3} \cdot$ Chongguo Tian $^{1} \cdot$ Xiaohui Pan $^{1} \cdot$ Jianhui Tang ${ }^{1}$ (D)
}

Received: 30 July 2018 / Accepted: 1 October 2018 / Published online: 30 October 2018

(C) Springer-Verlag GmbH Germany, part of Springer Nature 2018

\begin{abstract}
Located in the Shandong Province, North China, the Xiaoqing River is heavily contaminated by industrial wastewater and domestic sewage. However, it plays a significant role with regard to irrigation for agriculture in the river basin. In this study, spatial distribution, sources, and the ecological risk of aqueous polycyclic aromatic hydrocarbons (PAHs) in the Xiaoqing River Basin were investigated from the headwaters to the estuary. Fifteen USEPA priority PAHs (except naphthalene) were quantified in water particulate and soluble phases and in sediment samples. $\Sigma_{15}$ PAHs concentrations in the sediment varied from 17.15 to $3808.01 \mathrm{ng} / \mathrm{g}$ dry weight (dw), with an average of $988.72 \mathrm{ng} / \mathrm{g} \mathrm{dw}$, suggesting severe pollution of the Xiaoqing River in comparison with other rivers worldwide. The composition of PAHs was characterized by the high abundance of 4-ring and 5ring PAHs in sediments and 2-ring and 3-ring PAHs in water. Industrial wastewater is a significant source of PAHs. In the river section, point source was the main factor affecting the distribution of PAHs, while in the estuary region, estuarine turbidity maximum zone (ETM), riverine flow and discharge, and its hydrodynamic parameters play more key roles on PAH levels. Molecular diagnostic ratios have proved that PAHs in sediments were derived from mixed sources, primarily a combination of several combustion processes. Toxicity equivalency concentrations (TEQs) and Ecological risk assessment by Sediment Quality Guidelines indicated that PAHs in sediments might have certain unfavorable effects on ecosystems in certain sites.
\end{abstract}

Keywords PAHs · Xiaoqing River · Water sediment partition · Turbidity maximum zone $\cdot$ Ecological risk

\section{Introduction}

Polycyclic aromatic hydrocarbons (PAHs) are organic pollutants containing two or more benzene rings. They are increasing

Responsible editor: Philippe Garrigues

Electronic supplementary material The online version of this article (https://doi.org/10.1007/s11356-018-3379-y) contains supplementary material, which is available to authorized users.

Jianhui Tang

jhtang@yic.ac.cn

1 Key Laboratory of Coastal Environmental Processes and Ecological Remediation, Yantai Institute of Coastal Zone Research, Chinese Academy of Sciences, 17 Chunhui Road, Laishan District, Yantai 264003, People's Republic of China

2 University of Chinese Academy of Sciences, Beijing 100049, China

3 State Key Laboratory of Organic Geochemistry, Guangzhou Institute of Geochemistry, Chinese Academy of Sciences, Guangzhou 510640, China concerns across the world owing to their widespread distribution in the environment media and adverse effects on ecosystem and human health (Meyer et al. 2011). Most of them have carcinogenic, teratogenic, and mutagenic potential, with other properties such as bioaccumulation. They are not easily degradable in the environment (Wang et al. 2013) (Man et al. 2013) (Lau et al. 2014). Sixteen among them have been classified as priority pollutants by the United States Environmental Protection Agency (US EPA). PAHs exist in several environmental media, and they can enrich on dissolved phase, particle phase, and sediment in aquatic systems (Zhou et al. 1998). In recent decades, with the widespread application of fossil fuels (coal, oil, gas, etc) under the soaring demands from the industry and transportation sector, the quantity of PAHs discharged into the environment has increased rapidly, and increasingly, more attentions have been paid to the PAH pollution status and ecological risk in the environment (Tong et al. 2017) (Zeng et al. 2018).

Sources of PAHs in the environment are mainly classified into pyrogenic and petrogenic. Pyrogenic sources include the combustion process of fossil fuels, and uncompleted combustion 
of organic matters (such as wood, coal, and oil). Petrogenic source is ascribed to petrogenic products, including oil spillage and its refined production (Alebic-Juretic 2011). In addition, PAHs can also originate from surface runoff, industrial wastewater discharges, domestic sewage, atmospheric transportation, and deposition of exhaust and smoke (Zakaria et al. 2002) (Doong and Lin 2004). Among these, industrial and domestic emissions are the main sources. Petroleum refinery processes in petrochemical plants can release large quantities of PAHs into the surrounding environment. Power plant and ironwork processes, in which coal is used as a major energy source, can result in PAH contamination. All of these have caused serious ecological threats to the water environment, and even human health through personal exposure and food chains (An et al. 2016). Owing to their low vapor pressure, high hydrophobicity, and high octanol water partition coefficient, high-molecular PAHs are easily adsorbed on particles and enriched in sediments. River sediments are one of their main environmental sinks. PAHs in sediments can resuspend and re-dissolve in the overlying water with intense water turbulence. Therefore, it is urgent to search for the origin and distribution of PAHs in the aquatic environment.

Xiaoqing River in Shandong Province is one of the most contaminated rivers globally and in China, in terms of water quality and loading of petroleum hydrocarbon into the coastal sea. Xiaoqing River is the second largest river that drains into the Laizhou Bay, after the Yellow River. Xiaoqing River plays an important role in flood discharge, drainage, shipping, irrigation, sewage management, and so on. It is the main drainage outlet of Ji'nan, the capital city of Shandong province. Among the rivers discharged into the Laizhou Bay, Xiaoqing River is the most severe in terms of pollution status (Pan et al. 2010). Laizhou Bay has been badly polluted by anthropogenic contaminants from wastewater and rivers that drained into the bay since the 1970s (Jiang et al. 2017). Rapid urbanization and widespread industrial and agricultural campaigns have brought severe environmental damages and ecological risks to the local watershed in recent years. There are several energy-consuming enterprises, with the petrochemical plant, ironwork plant, and power plant being the three typical industries in this region. Over the last 20-30 years, the ecological environment of the Xiaoqing River has been seriously collapsed owing to the large quantities of industrial and domestic wastewater discharged. It is imperative, thus, to assess the contamination status and remediate the polluted environment.

Concentration, composition, and ecological risk of PAHs in the Xiaoqing River Basin was conducted in this study. The aim of this study was to evaluate the influence of industrial activities on PAH pollution in the nearby river, while evaluating the pollution status, to characterize the PAH transportation processes from the headwaters to the estuary, and to assess the ecological effects of PAH pollution on the local ecosystem.

\section{Material and methods}

\section{Sample collection}

To study the distribution and contamination of PAHs in the Xiaoqing River, sediment and water samples were collected from 30 sites in April, 2014. Details of the sampling strategy and stations can be found in previous publications (Jiang et al. 2017)(Zhen et al. 2018). Here, we provide a brief introduction. Thirty sites, containing 19 sites located in the river sector (X1X19) and other 11 sites (X20-X30) located in the estuary of the Xiaoqing River and Laizhou Bay, were selected (Fig. 1). There is a floodgate between sites X19 and X20 in the river channel to prevent seawater intrusion to the upstream sector. The positions of all sampling sites are shown in Fig. 1, along with some additional information. Information on the factories in the Xiaoqing River Basin is provided in Table S1.

Approximately $500 \mathrm{~g}$ of surface sediments (top $5 \mathrm{~cm}$ ) was obtained using stainless-steel sampler, which was subsequently sealed in polyethylene (PE) bags. Surface water was collected with stainless steel bucket for $20 \mathrm{~L}$. All sediments were kept in refrigerator under $-20{ }^{\circ} \mathrm{C}$ until next analysis. Water samples were kept in brown jar (at about $4{ }^{\circ} \mathrm{C}$ ) and transferred to laboratory within $24 \mathrm{~h}$. Water samples initially pass through a glass fiber filter (GFF, Whatman, $0.7-\mu \mathrm{m}$ pore size) to collect particles, and then through an Amberlite ${ }^{\circledR}$ XAD-2 resin column $(30 \times$ $4 \mathrm{~cm}$ i.d., approximately $30 \mathrm{~g}$ of resin) to concentrate the dissolved PAHs.

\section{Extraction and analysis}

Sediment samples were freeze-dried, pulverized, and homogenized before extraction. Subsequently, all samples were Soxhlet extracted by dichloromethane (DCM) for $24 \mathrm{~h}$. Before extraction, Naphthalene- $\mathrm{D}_{8}$, Acenaphthene- $\mathrm{D}_{10}$, Phenanthrene- $\mathrm{D}_{10}$, Chrysene- $\mathrm{D}_{12}$, and Perylene- $\mathrm{D}_{12}$ were added as surrogate standards, while activated copper and zeolite were added to remove elemental sulfur from the sediment and prevent violent boiling, respectively. The extracts were concentrated to approximately 2 $3 \mathrm{~mL}$ by rotary evaporator. Next, concentrated extracts were purified through a column including $1 \mathrm{~g}$ of sodium sulfate and $2.5 \mathrm{~g}$ (10\% deactivated) of silica gel. The extracts were concentrated to about $1 \mathrm{~mL}$ in iso-octane finally. Prior to the instrumental analysis, internal standard (hexamethylbenzene) added into every sample. An Agilent 7890A gas chromatograph (GC), coupled with a 5975C mass selective detector (MSD), was used to identify and quantify PAH congeners (information in Supplementary materials).

After removing carbonates by hydrochloric acid $(\mathrm{HCl})$, the total organic carbon (TOC) of sediment was determined using an elemental analyzer (CHNS Vario Ei III, Elementar). Water samples were filtered through a cellulose acetate membrane (pore 
Fig. 1 Map of the sampling stations in the Xiaoqing River Basin

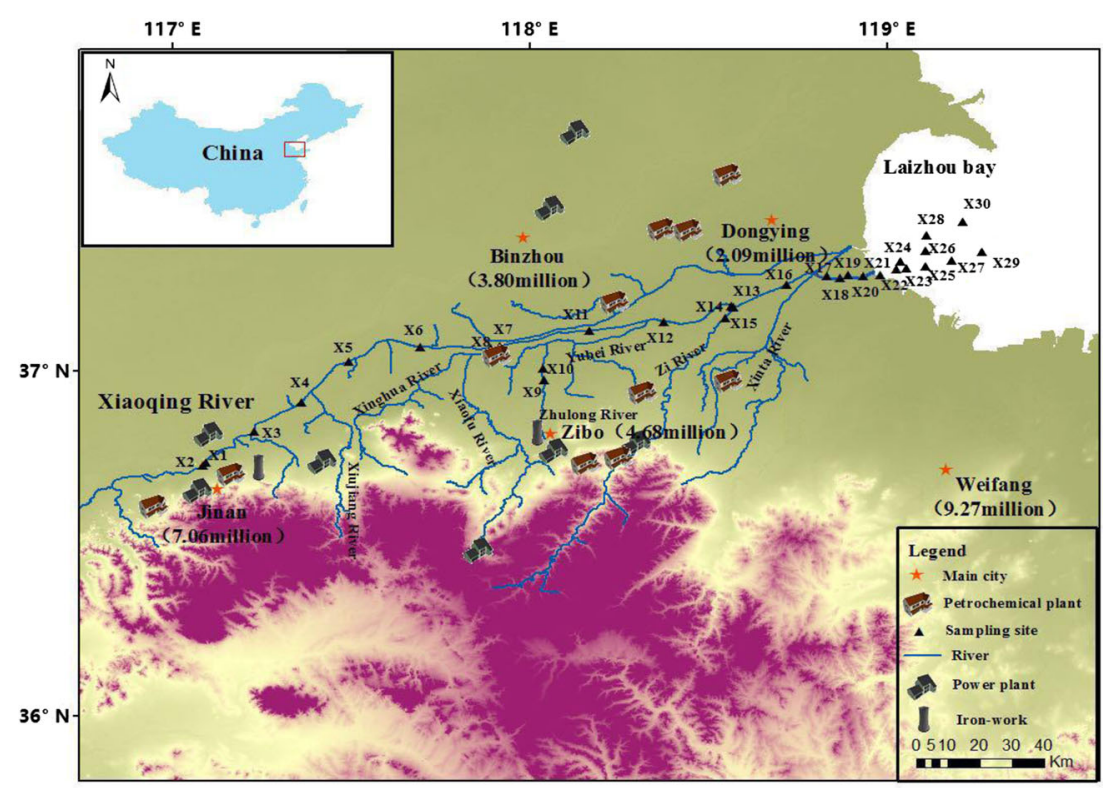

size: $0.45 \mu \mathrm{m}$ ), and then dissolved organic carbon (DOC) was also measured with the Vario TOC analyzer.

\section{Quality assurance and quality control}

All analytical procedures and the obtained data were subjected to quality control. Standard PAH mixture purchased from Supelco, Bellefonte, USA, including 15 USEPA priority PAHs, was subjected to the $\mathrm{QA} / \mathrm{QC}$ procedure. The standard $\mathrm{PAH}$ mixture contained Acy (acenaphthylene), Acen (acenaphthene), Flu (fluorene), Phe (phenanthrene), Ant (anthracene), Fluo (fluoranthene), Pyr (pyrene), BaA (benzo(a)anthracene), Chr (chrysene), $\mathrm{BbF}$ (benzo(b)fluoranthene), $\mathrm{BkF}$ (benzo(k)fluoranthene), $\mathrm{BaP}$ (benzo(a)pyrene), DahA (dibenzo(a,h)anthracene), InP (indeno(1,2,3-cd)pyrene), and BghiP (benzo(g,h,i)-perylene). The method detection limits (MDLs) were calculated based on the average of the solvent blanks plus three standard deviations of the blanks. Information of MDL is provided in Table S2. The average surrogate recoveries were $84.58 \pm 17.94 \%$ for Nap- $\mathrm{D}_{8}$, $94.42 \pm 11.35 \%$ for Acen- $\mathrm{D}_{10}, 93.61 \pm 12.16 \%$ for Phe- $\mathrm{D}_{10}$, $89.67 \pm 9.88 \%$ for $C h r-D_{12}$, and $88.96 \pm 13.78 \%$ for Pery- $\mathrm{D}_{12}$ in solvent blanks. The values in all samples were not corrected for recoveries.

\section{Results and discussion}

\section{PAHs in sediment and water}

\section{Concentration and distribution of PAHs in sediment}

Fifteen priority PAHs were investigated in sediments from various sampling locations along the Xiaoqing River (Fig. 2).
According to the International Agency for Research on Cancer, six among these 15 PAHs have a potential carcinogenic effect on human beings (Flu, BbF, BkF, BaP, InP, and BghiP). Discussions on these six PAHs are emphasized in this study.

$\Sigma_{15} \mathrm{PAH}$ concentrations varied greatly, depending on the sampling locations. The concentrations of $\Sigma_{15}$ PAHs in the sediments ranged from 17.15 (X29) to $3808.01 \mathrm{ng} / \mathrm{g} \mathrm{dw}$ (X3), with a mean value of $988.72 \mathrm{ng} / \mathrm{g}$ dw. $\Sigma_{15}$ PAHs in sediment samples were significantly higher at the riverine sites (mean value: $1557.94 \mathrm{ng} / \mathrm{g} \mathrm{dw}$ ) than at the estuarine sites (mean value $166.50 \mathrm{ng} / \mathrm{g} \mathrm{dw}$ ). The concentrations of individual PAH among all samples were significantly different. The PAH congeners based on the decreasing order of their mean concentrations are: Fluo $>\mathrm{Pyr}>\mathrm{Chr}>\mathrm{Phe}>\mathrm{BbF}>\mathrm{BghiP}>$ $\mathrm{BaP}>\mathrm{BaA}>\mathrm{Ant}>\mathrm{InP}>\mathrm{Flu}>\mathrm{BkF}>$ Acen $>$ Acy $>$ DahA. Fluo had the highest concentration, ranging from 3.09 to $425.61 \mathrm{ng} / \mathrm{g} \mathrm{dw}$, with average value of $133.81 \mathrm{ng} / \mathrm{g} \mathrm{dw}$. The highest $\Sigma_{15}$ PAH concentration was observed at site X3 (3808.01 ng/g dw), followed by X5 (3397.17 ng/g dw), X18 (2354.83 ng/g dw), and X11 (2193.07 ng/g dw), while the lowest concentrations were recorded at the Laizhou Bay sites of X26, X27, X28, X29, and X30 (with a mean value of $21.28 \mathrm{ng} / \mathrm{g} \mathrm{dw}$ ). Detailed information on PAH concentrations in the sediments at sampling sites is shown in Table S4. The maximum value was more than 100 times higher than the minimum value.

In sediment samples, the highest concentration of PAHs was presented in $\mathrm{X} 3$, which might be ascribed to the point inputting contamination. There are several large factories in the Ji'nan section of Xiaoqing River, including petrochemical plants, power plants, and ironwork plants, which could aggravate the pollution of PAHs in the Xiaoqing River to a certain extent. In addition, there is a wastewater treatment plant 

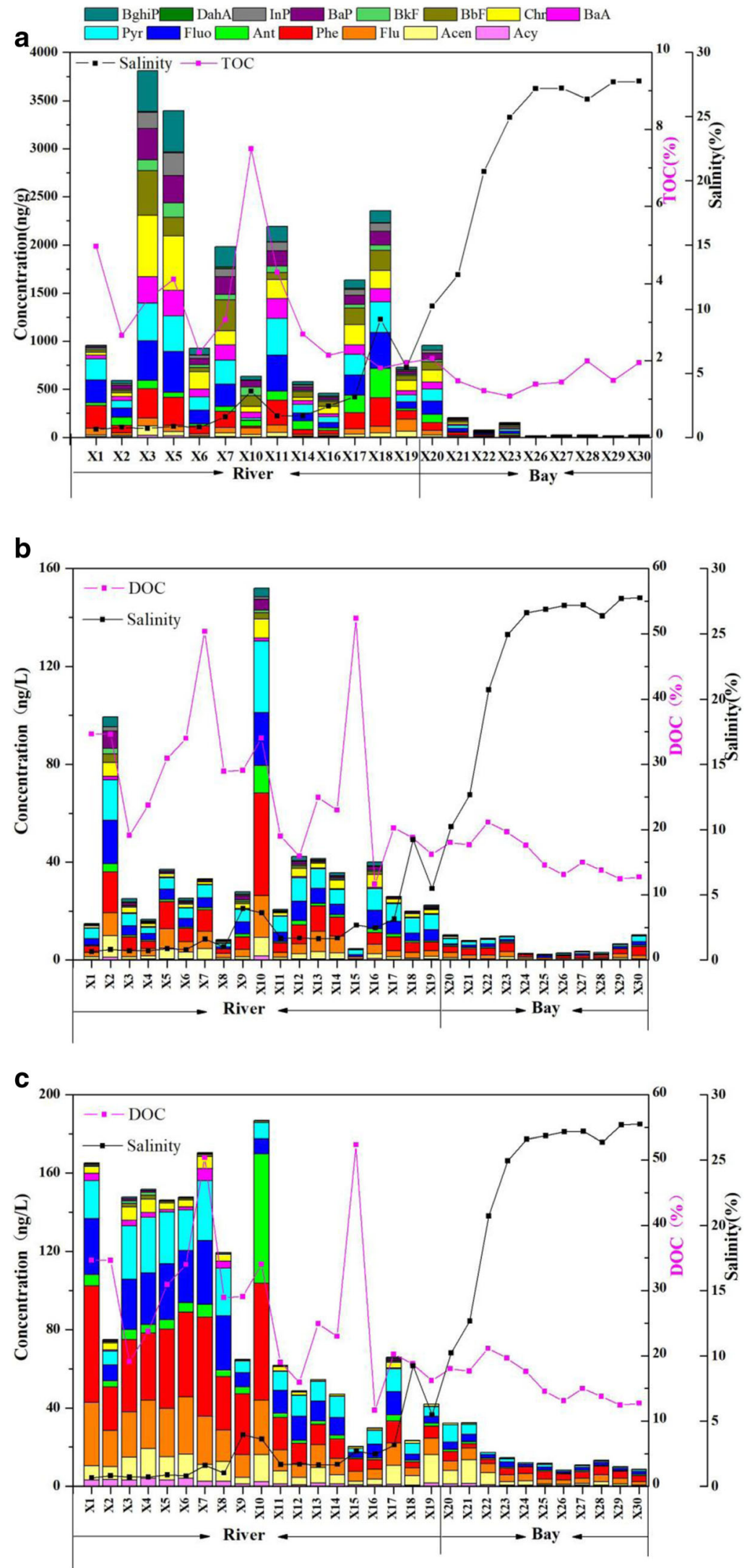

Fig. 2 Concentrations of PAHs in a sediment, $\mathbf{b}$ particle phase in water, $\mathbf{c}$ dissolved phase in water, from the Xiaoqing River Basin 
(WWTP) upstream of station X3 and receives urban wastewater from Ji'nan, which has a population of 7.06 million. High $\Sigma_{15} \mathrm{PAH}$ concentrations were also found at sites X17 and X18, which were located downstream of the Xiaoqing River. The Shengli, Shenchi, Kenli, Jinbo, Xintai, and Huaxing petrochemical plants, as well as Datang and Huaneng power plants, are located upstream of these sites, which might result in high loads of PAHs in the Xiaoqing River. Slightly high concentrations of $\Sigma_{15} \mathrm{PAHs}$ were found at site X11, which can be attributed to the several upstream tributaries collected near X11. The $\Sigma_{15}$ PAHs concentrations in the mouth of Xiaoqing River estuary samples (Fig. 2; X20-X23) were higher than those samples from seaward sites (X24-X30). The concentrations of $\Sigma_{15} \mathrm{PAHs}$ in the estuarine sediments decreased slowly towards the Laizhou Bay due to the Seawater dilution effecting.

The $\Sigma_{15}$ PAH concentrations decreased as the overlaying seawater salinity increased sharply from sites X20 to X23. Figure 2 shows the dramatic variation in salinity between sites X20 and X23, which may be attributed to the turbidity maximum zone (TMZ) in this area (Taupp et al. 2017). Hermes and Sikes (2016) reported that the maximum value of particulate organic carbon (POC) occurred in the water of TMZ (Hermes \&Sikes 2016). The higher $\Sigma_{15} \mathrm{PAHs}$ concentrations between sites X20 and X23 than at other estuarine sites might be due to the scavenger effect of particles in the TMZ and the dilution effect downstream of TMZ.

The specific description of sediment contamination level assessed by 15 PAH concentration is displayed in Supplementary materials. The contamination status of sediment from the riverine sample in this study was high to very high, while for bay sample was low to moderate. Compared with other rivers all over the world (Table S3), the average concentration of 15 PAHs in Xiaoqing River section was similar to those in the Shenzhen River (Deng et al. 2014); lower than those in the Haihe River (Qian et al. 2017), Ziyaxin River (Liu et al. 2013a), Prai River (Keshavarzifard et al. 2014), and Ammer River (Liu et al. 2013b); and higher than those in Bohai Bay (Hu et al. 2010) and Songhua River (Zhao et al. 2014). Clearly, the comparison suggested that PAH pollution in the Xiaoqing River was severe and at a high range.

\section{Composition pattern of PAHs in the sediment}

PAHs in sediment were dominated by 4-, 5-, and 6-ring congeners, followed by 2- and 3-ring PAHs (low molecular weight PAHs, LPAHs) (Fig. 3). PAHs with high molecular weight (HPAHs, 4- to 6-ring) in sediments were abundant, constituting $57.46-86.26 \%$ of $\Sigma_{15}$ PAHs, which was attributed to the high organic carbon-water partition coefficients and high hydrophobicity of HPAHs. The high-ringed PAHs have poorer biodegradability and lower solubility than the low- ringed PAHs, readily to be enriched in sediments (Zong et al. 2014).

Composition patterns of PAHs contain their source information, which can be used to trace their sources (Cao et al. 2005). LPAHs are believed to be originated from petroleum and low-temperature pyrolytic combustion process and HPAHs majorly be originated from high-temperature combustion inputting (Mai et al. 2003). Relative abundance of PAHs by ring size is showed in Fig. 3. High percentages of LPAHs may indicate the contribution of petroleum activities at some sites. Furthermore, higher concentrations of HPAHs than LPAHs have been commonly showed in sediments (Yuan et al. 2016). The composition of PAHs demonstrated a significant difference between the percentages of HPAHs $(72.5 \%)$ and LPAHs $(27.5 \%)$, which was in agreement with the other results reported in the aquatic sediments (Malik et al. 2011).

\section{Concentration and distribution of PAHs in water}

$\Sigma_{15}$ PAHs concentrations in water varied slightly compared with those in sediment samples at various sampling sites, ranging from $10.40 \mathrm{ng} / \mathrm{L}$ (X26) to $337.31 \mathrm{ng} / \mathrm{L}$ (X10), with a mean value of $89.63 \mathrm{ng} / \mathrm{L}$. PAH congeners arranged in decreasing order based on mean concentrations are Phe $>$ Flu $>$ Pyr $>$ Fluo $>$ Acen $>$ Ant $>$ Chr $>$ Acy $>$ BaA $>$ BaP $>$ BghiP $>$ $\mathrm{BbF}>\mathrm{BkF}>\mathrm{InP}>\mathrm{DahA}$. The highest concentration was found at site X10 (337.31 ng/L), followed by X7 (203.54 ng/L), X5 (182.93 ng/L), and X1 (179.96 ng/L), while lower concentrations were recorded at sites X24, X25, X26, X27, X28, X29, and X30. Detailed information on the PAH concentrations in water at various sampling stations is shown in Tables S5 and S6.

$\mathrm{X} 10$ is located in a tributary of the Xiaoqing River-the Zhulong River. The industrial park of Zibo (a city with 4.68 million inhabitants) is located upstream of the Zhulong River. This could be the main reason for the high concentrations at $\mathrm{X} 10$, owing to industrial and domestic emission. The highest concentration of perfluorooctanoic acid (PFOA) was found at site X10 in the same field campaign (Heydebreck et al. 2015), which can be attributed to an industrial point source. Slightly high concentrations of $\Sigma_{15} \mathrm{PAHs}$ were found at site X7, which might due to the proximity of the Jincheng Petrochemical plant. With the increase in salinity, $\Sigma_{15} \mathrm{PAH}$ concentrations in the estuarine water samples declined slowly towards the Laizhou Bay due to the seawater dilution effecting. Compared with those samples in the estuarine and bay sites, $\Sigma_{15}$ PAH concentrations in the river section (both in water and sediment) varied sharply.

\section{Composition pattern of PAHs in particle and dissolved phases}

A comparison of the PAH concentrations in particle and dissolved phases in water samples from various locations is 

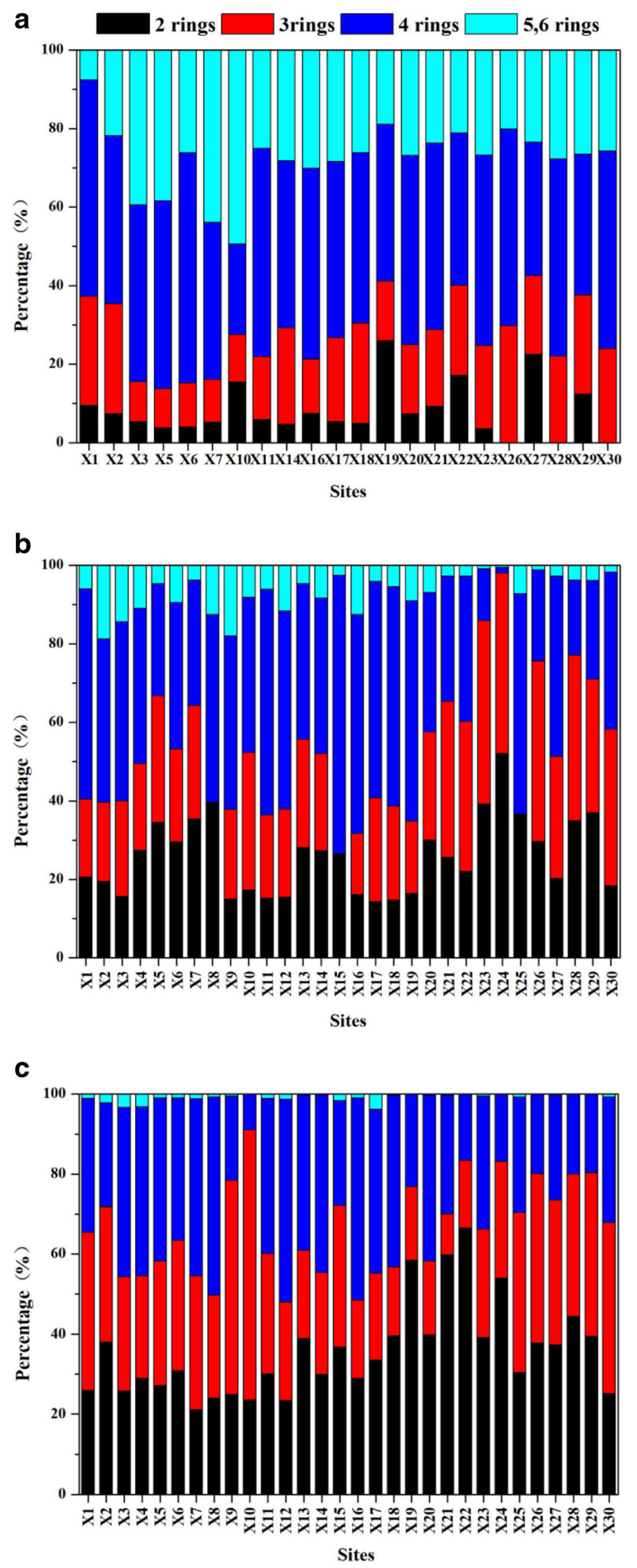

Fig. 3 Percentage variation of LMW (2-3-ring) and HMW (4-6-ring) PAHs in the Xiaoqing River (a surface sediments. b Particle phase in water. c Dissolved phase in water) 
provided in Fig. 2. Concentrations of $\Sigma_{15} \mathrm{PAHs}$ in the dissolved and particle phases ranged from 8.24 to $186.74 \mathrm{ng} / \mathrm{L}$ and 2.17 to $151.95 \mathrm{ng} / \mathrm{L}$, with a mean value of 64.65 and $25.20 \mathrm{ng} / \mathrm{L}$, respectively. LPAHs were predominant in the water, accounting for $39.28-85.62 \%$ of the 15 PAHs. Fourring PAHs accounted for $14.25-54.03 \%$ of the 15 PAHs, while those with five to six rings constituted only 0.15 $6.69 \%$. The PAH composition patterns in this study are similar to those in other studies (Zhao et al. 2014) (Li et al. 2015b).

In dissolved phase, two to three ring PAHs were predominant accounting for $48.03-90.96 \%$ of the $\Sigma_{15}$ PAHs. Four-ring PAHs accounted for $8.97-49.53 \%$ of the $\Sigma_{15} \mathrm{PAHs}$, while those with five to six rings constituted only $0-3.88 \%$ as shown in Fig. 3. The mean proportion of HPAHs was $33.73 \%$. In particulate phase, the HPAHs were predominant, with a mean proportion of $47.52 \%$ of $\Sigma_{15} \mathrm{PAHs}$, which was ascribed to high hydrophobicity and the high organic carbon-water partition coefficients of the HPAHs. Considering their high hydrophobicity, the PAHs in water are prone to adsorb on the suspended particle matter, subsequently accumulating in sediments contributing to them being difficult to degrade (Retnam et al. 2013).

HPHAs were significantly more dominant in sediments than in water. High proportions of LPAHs are commonly dominant in the dissolved phase owing to their higher water solubility and vapor pressure compared with that of the HPAHs (Nagy et al. 2013). This is because HPAHs are difficult to degrade and have high hydrophobic property, contributing to them to be accumulated in the sediments more readily (Luo et al. 2008) (Parinos et al. 2013). However, LPAHs in water easily degrade in about 2 days (Witt et al. 2001). Considering LPAHs are more labile and evaporation than the HPAHs, the prevalence of LPAHs may demonstrate that they originate from local sources, for example wastewater discharge, leakage of oil, and atmospheric deposition.

\section{Partition of PAHs between dissolved and particulate phases}

Studies of the distribution of PAHs in the particulate water phase can obtain detailed information about the relationship between source and sink (Chen et al. 2016). In the process of particle-water phase partition, the observed PAH $\log \mathrm{K}_{\mathrm{oc}}$ value in the Xiaoqing River section presented an increasing tendency as molecular weight increased, which might indicate that the chemical structure or property is a factor affecting the accumulation of PAHs in particulate organic carbon. The partition of particulate water in aquatic environment is a significant transportation process affecting the fate of hydrophobic organic compounds. As shown in Fig. 4, with increasing of molecular weight, this trend is in accordance with the theoretical value of $\log \mathrm{K}_{\mathrm{oc}}$ (data from US EPA).

Therefore, the normalized partition coefficient of organic carbon $\left(\mathrm{K}_{\mathrm{p}}=\mathrm{C}_{\mathrm{s}} \mathrm{C}_{\mathrm{w}}^{-1} ; \mathrm{K}_{\mathrm{oc}}=\mathrm{K}_{\mathrm{p}} \mathrm{f}_{\mathrm{oc}}^{-1}, \mathrm{~L} \mathrm{~g}^{-1}\right)$ is widely used to

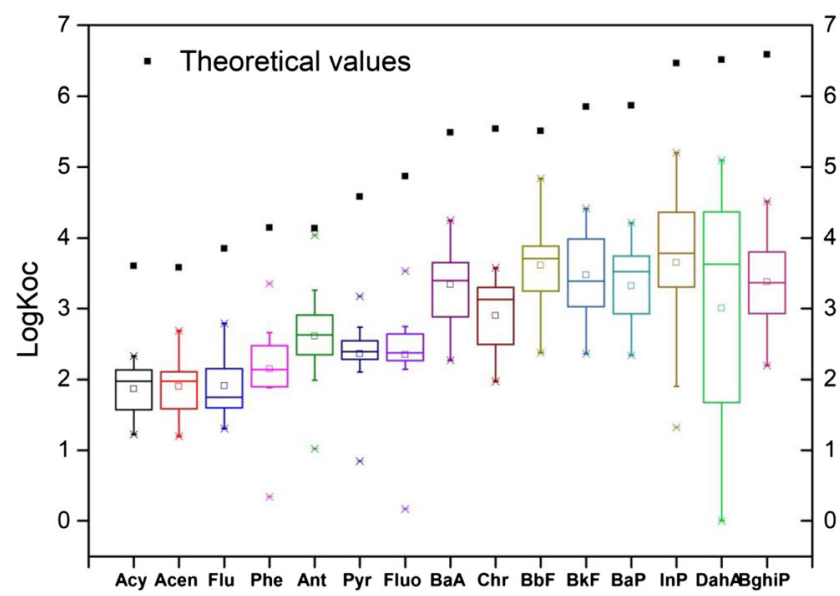

Fig. 4 Difference between theoretical and observed $\mathrm{K}_{\mathrm{oc}}$ values for PAHs in the Xiaoqing River

show the PAH distribution in system of particle and water. As shown in Fig. 5, there was a significant correlation $(p<0.05)$ between the measured $\log \mathrm{K}_{\mathrm{oc}}$ and $\log \mathrm{K}_{\mathrm{ow}}$ (octanol water partition coefficient) of PAHs in Xiaoqing River section. Other studies have also found this relationship in particulate water partition (Ya et al. 2017). The measured values $\log \mathrm{K}_{\mathrm{oc}}$ were lower than the theoretical values, indicating that the chemical partition between dissolved and particulate phase in the aquatic system is not balanced yet.

\section{Correlation analysis for individual PAHs and physicochemical indicators in sediment and water}

The correlation coefficient matrix of individual PAH in sediments presented that LPAH, HPAH, and $\Sigma_{15}$ PAHs have remarkable correlation, possibly suggesting similar characteristics, fate, and source, except for Ant. The physicochemical properties of PAHs and the characteristics of sediments will have a certain effect on the concentration of PAHs in

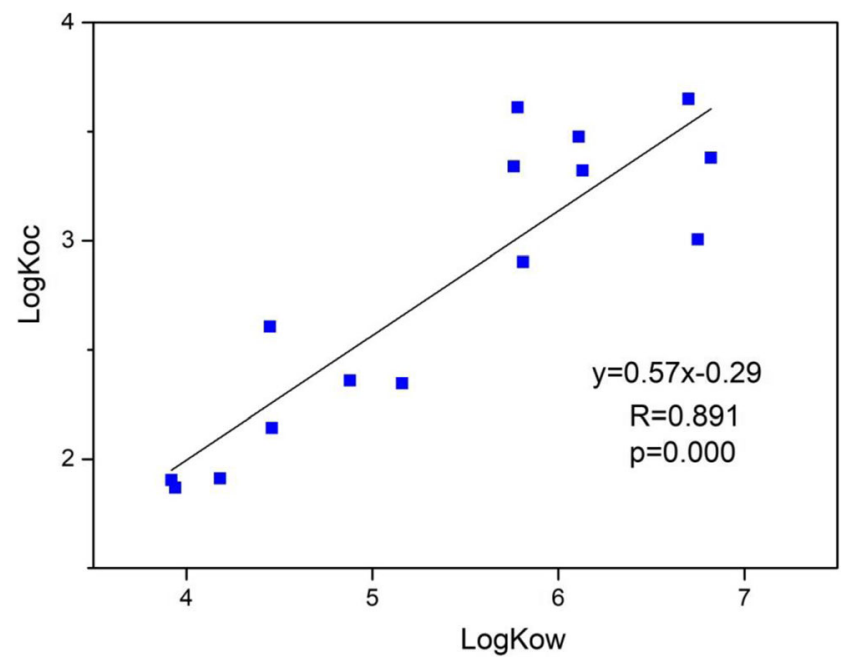

Fig. 5 Correlations between measured $\log \mathrm{K}_{\mathrm{oc}}$ and $\log \mathrm{K}_{\mathrm{ow}}$ values of PAHs in the Xiaoqing River section 
sediments. The relationship between PAHs and organic carbon in water and sediment was studied for investigating the effect of organic carbon on the migration and fate of PAHs in aquatic system. TOC concentrations in the sediment ranged from 1.07 to $7.50 \%$, with an average value of $2.60 \%$. In this study, the correlations $(p>0.05)$ between $\Sigma_{15}$ PAHs and TOC were not significant in the sediments, possibly indicating that organic carbon has little effect on PAHs in sediments. Information on the correlation coefficient matrixes for 15 PAHs in the sediment is shown in Table S7.

Remarkable positive correlation was presented between LMW, DOC, CDOM, and $\Sigma_{15}$ PAHs in the water-dissolved phase, except for Ant, InP, and DahA. DOC concentrations in the river sites and estuarine sites ranged from 6.69 to $31.51 \mathrm{mg} / \mathrm{L}$ and from 2.75 to $9.11 \mathrm{mg} / \mathrm{L}$, respectively, for the collected samples. Positive correlations $(p<0.05)$ for $\Sigma_{15}$ PAHs in the dissolved phase with regard to DOC might suggest that the organic carbon influenced the $\mathrm{PAH}$ partitioning in water (Fig. S1) (Zhang et al. 2017). In addition, DOC and several individual low-ring PAHs also share significant relationships, such as Phe, Flu, and Ant, which can potentially be ascribed to the higher water solubility and lower organic carbon-water partition coefficients of low-ring PAHs.

Dissolved organic matter (DOM) affects the environmental transport and fate of various organic pollutants in the aquatic system owing to its heterogeneous properties (Jiang et al. 2017). In the Xiaoqing river-estuary systems, the fate of environmental organic pollutants was influenced by DOM. The DOM properties and their correlations with mercury were investigated using the same batch of samples (Jiang et al. 2017). CDOM abundance can be simply denoted as $\alpha(355)$. The $\alpha(355)$ ranged from 0.22 to $16.71 / \mathrm{m}$, being significantly higher in the riverine stations than in the estuarine stations. CDOM displayed a significant correlation $(p<0.05)$ with the $\Sigma_{15}$ PAHs in the dissolved-phase samples (Fig. S2). Information on the correlation coefficient matrixes for individual PAHs in dissolved phase is shown in Table S8.

\section{Spatial distribution and source identification of PAHs by isomer ratios}

Characteristics of PAH patterns in sediments represent various emission sources. In order to distinguish pyrolytic inputting from petrogenic sources, molecular indices based on the isomer ratios have been widely applied (Yunker et al. 2002) (Li et al. 2015a). To identify the sources of PAHs, calculation and comparison about ratios of Fluo/(Fluo + Pyr), Ant/(Ant + $\mathrm{Phe}), \mathrm{InP} /(\mathrm{InP}+\mathrm{BghiP})$, and $\mathrm{BaA} /(\mathrm{BaA}+\mathrm{Chr})$ were conducted (Fig. S3). Phe is more stable in thermodynamics than Ant and the higher concentration of Phe suggests that PAHs majorly come from petroleum sources (Yang et al. 2013). It is believed that Ant/(Ant $+\mathrm{Phe})>0.10$ suggests combustion sources, while Ant $/(\mathrm{Ant}+\mathrm{Phe})<0.10$ indicates petrogenic sources (Yunker et al. 2002). Generally, petroleum inputting presents a fairly low Ant/(Ant + Phe) ratio.

If Fluo/(Fluo + Pyr) ratios were $>0.5,0.5-0.4$, and $<0.4$, the pollution was owing to organic matter combustion (grass, wood, and coal), petroleum combustion (fossil fuel and crude oil), and petrogenic sources, respectively. In addition, InP/ $($ InP + BghiP $)<0.20$ suggests petroleum sources, while $>$ 0.50 is considered to come from grass, wood, and coal combustion. Values $(0.20-0.50)$ are indicative of petroleum combustion (fossil fuel and crude oil) (Yunker et al. 2002). BaA/ $(\mathrm{BaA}+\mathrm{Chr})<0.20$ usually indicates petroleum sources, and $0.20-0.35$ suggests petroleum or combustion sources, while $>$ 0.35 is potentially ascribed to combustion (Wang et al. 2015).

Acy and Acen are majorly originated from the leakage of petroleum and oil-related production owing to the petrochemical plant (Steinhauer and Boehm 1992). In the vicinity of the power plant, the ironwork plant, and the petrochemical plant, Fluo, Pyr, BaA, Chr, BbF, BkF, BaP, DahA, InP, and BghiP came from combustion of petroleum and coal (Khalili et al. 1995), and the Ant and Acy have certain relationship with the combustion of organic matters (Harrison et al. 1996). Owing to the high frequency of traffic and transportation, concentrations of Phe and Flu were affected heavily by fossil fuel combustion (Simcik et al. 1999).

In this study, the ratio Fluo/(Fluo + Pyr) ranged from 0.14 to 0.57 , with a mean of 0.51 , while the Fluo/(Fluo + Pyr) ratio in site X10 was $<0.4$, which implies that the contamination was mainly a result from petroleum-based inputting. This may be attributed to the Qilu petrochemical plant, located upstream in Zibo. Coincidently, the concentration level of Acen and Acy in site X10 was medium, while it was slightly high in site X7, probably owing to proximity with the Jincheng petrochemical plant. Meanwhile, the ratio at the other sites was between 0.48 and 0.57 , which suggests that the contamination was a result from the combustion of organic matters and petroleum products.

With regard to the ratios of Ant/(Ant + Phe), all samples showed values higher than $0.10(0.11-0.78)$, suggesting pyrolytic sources (combination combustion of petroleum and organic matters). The ratios of $\mathrm{BaA} /(\mathrm{BaA}+\mathrm{Chr})$ at sites $\mathrm{X} 3, \mathrm{X} 5$, $\mathrm{X} 6, \mathrm{X} 16, \mathrm{X} 17$, and X19 ranged from 0.28 to 0.32 , which indicates that the pollution was from either petroleum sources or combustion inputting. Meanwhile, at the other sites, the ratio was $>0.35$, suggesting combustion sources. The ratios of $\mathrm{InP} /(\mathrm{InP}+\mathrm{BghiP})$ ranged from 0.01 to 0.41 . The value at site $\mathrm{X} 1$ was $<0.2$, suggesting that the contamination originates from petroleum inputs, which might be attributed to the Changcheng oil refinery and petrochemical plant in Ji'nan, while that in most of the other sites was between 0.20 and 0.50 , indicating petroleum combustion sources.

In our study, the ratios of Fluo/(Fluo + Pyr) and Ant/(Ant + Phe) in water demonstrated that the PAHs in the particle phase originated from either petroleum or combustion sources, and 
the PAHs in the dissolved phase were predominantly from pyrolytic inputs, as showed in Fig. S4. The study shows more pyrolytic PAHs in the particle phase than petroleum ones, which might be due to pyrolytic PAHs easily enriched in particle phase of water compared with dissolved phase. The inputting of petrogenic-derived PAHs can promote the LPAHs adsorb in the dissolved phase, resulting in a large variety of LPAHs in the water column (Chen et al. 2016).

Based on the analysis of diagnostic ratios, PAHs in surface sediments of Xiaoqing River were mostly from the combination sources that were characterized by combustion of organic matter and petroleum.

\section{Toxicity and potential ecological risk of PAHs}

\section{Toxicity based on the BaP concentrations}

In view of the concentrations of potentially carcinogenic PAHs (BaA, Chr, BbF, BkF, BaP, DahA, and InP), the evaluation of sediment toxicity was studied (Qiao et al. 2006). The $\Sigma \mathrm{cPAH}$ concentrations varied from 4.19 to $1990.65 \mathrm{ng} / \mathrm{g} \mathrm{dw}$, with an average concentration of $425.61 \mathrm{ng} / \mathrm{g} \mathrm{dw}$. Among the cPAHs, $\mathrm{BaP}$ is the most carcinogenic. Based upon $\mathrm{BaP}$, the calculation of PAH potential toxicity in sediments was conducted by the equation below, to represent the toxicity and bioaccumulation of priority PAHs, toxicity equivalency factors (TEFs), and toxicity equivalency concentrations (TEQs) (Tian et al. 2013).

$\mathrm{TEQ}_{\mathrm{BaP}} \mathrm{i}=\mathrm{Ci} \times \mathrm{TEF}_{\mathrm{BaP}} \mathrm{i}$,

$\mathrm{TEQ}_{\mathrm{PAH}}=\Sigma \mathrm{TEQ}_{\mathrm{BaP}} \mathrm{i}$,

Ecotoxicological risk of PAHs and the TEQi for carcinogenic PAHs in sediments was shown in Fig. S5. The maximum value occurred in the station $\mathrm{X} 3$. The results showed that the TEQ $\mathrm{PAHs}_{\mathrm{s}}$ of sampling sites varied from 1.02 to $439.02 \mathrm{ng} \mathrm{g}^{-1} \mathrm{dw}$. The high percentage of BaP in the TEQPAHs might imply that the matter $\mathrm{BaP}$ is useable to represent threats caused by PAHs in sediments. Among the various cPAHs, their contribution to the total TEQPAHs was in the below decreasing order: $\mathrm{BaP}$ (72.56\%), $\mathrm{BbF}(8.80 \%), \mathrm{BaA}$ (7.24\%), InP (3.93\%), BkF (3.19\%), DahA (3.06\%), and $\mathrm{Chr}(1.22 \%)$. Obviously, BaP was the dominant compound in the area, which could generate more concern due to its high toxicity.

\section{Potential ecological risk of PAHs}

Based upon the biological effects database for sediments evaluation, the Sediment Quality Guideline (SQG) was widely applied in aquatic and marine environments (Long et al. 2006) (MacDonald et al. 2000). The specific description of SQG is displayed in Supplementary materials.
As shown in Table S9, the concentrations of Flu and Acen at most sampling sites were in the intermediate (ERL-ERM) value (12 and 10 of the 22 sites, respectively), showing that negative ecological influence concerning Flu and Acen would happen occasionally in many sites of the Xiaoqing River. For Phe, Ant, $\mathrm{BaA}$, and $\mathrm{Chr}$, the concentrations were in value of ERL-ERM at certain sites (varying from two to five) suggesting that adverse biological effects could occasionally occur on organisms. No PAH was higher than the ERM value, suggesting that no highly adverse biological effects would occur frequently. The concentrations of Acy, Fluo, Pyr, BaP, and DahA were lower than the corresponding ERL at entire sites, suggesting that Acy, Fluo, Pyr, BaP, and DahA rarely have negative effects on aquatic organisms. The concentrations of 15 PAH were lower than the ERL value at sites X16, X21, X22, $\mathrm{X} 23, \mathrm{X} 26, \mathrm{X} 27, \mathrm{X} 28, \mathrm{X} 29$, and X30, with the samples showing little ecological threat. As for the rest of 13 sites, there were all at least one concentration of PAHs higher than the ERL value implying that adverse biological effects would happen. In particular, at sites X3, X5, X7, X11, X17, and $\mathrm{X} 18$, most PAH concentrations were between the ERL and ERM values, indicating fairly high probability of severe biological effects could occur at some time.

The results indicated that the sediment from all the sampling sites in Xiaoqing River has medium to high ecotoxicological risks, except for some moderately contaminated sites. In summary, relatively negative toxic effects could occur on the organisms and the ecosystems in the Xiaoqing River. As a result of intensifying anthropogenic activities along the river basin, PAH pollution is becoming increasingly serious and harmful to the health of the ecosystem. Some latent ecotoxicological risks of PAHs would inevitably exist in the area. Therefore, emphasizing and strengthening PAH monitoring and remediation is necessary in future.

\section{Conclusions}

This study investigated the occurrence and distribution of PAHs in water and sediment samples from the Xiaoqing River. The 15 PAH concentrations varied dramatically across the sampling sites. $\Sigma_{15}$ PAHs were moderately high compared with other rivers worldwide, implying severe PAH contamination in the Xiaoqing River. $\Sigma_{15} \mathrm{PAHs}$ at the riverine sites were higher than at the estuarine sites in both sediment and water samples. Significant correlation was showed between the observed $\log$ Koc and $\log$ Kow in particle-water partition. HPAHs were predominant in the sediment samples and LPAHs were abundant in the water samples. As for molecular ratios, Fluo/(Fluo + Pyr), Ant/(Ant + Phe), InP/(InP + BghiP), and $\mathrm{BaA} /(\mathrm{BaA}+\mathrm{Chr})$ were calculated at all sediment samples. The calculations suggest that the PAHs majorly originated from several combustion processes. In comparison with 
other reports, the sediments in the Xiaoqing River presented a medium to high potential toxicity. In the material circulation of earth, urban river system plays a significant role and can directly influence human health. In summary, we should pay more attention on the river system and further investigation should be developed.

Acknowledgements This study was supported by the Chinese Academy of Sciences (XDA11020402, XDA11020305 and KZZD-EW-14), and the National Science Foundation of China (No. 41773138).

\section{References}

Alebic-Juretic A (2011) Polycyclic aromatic hydrocarbons in marine sediments from the Rijeka Bay area, northern Adriatic, Croatia, 19982006. Mar Pollut Bull 62:863-869

An N, Liu S, Yin Y, Cheng F, Dong S, Wu X (2016) Spatial distribution and sources of polycyclic aromatic hydrocarbons (PAHs) in the reservoir sediments after impoundment of Manwan dam in the middle of Lancang River, China. Ecotoxicology 25:1072-1081

Cao ZH, Wang YQ, Ma YM, Xu Z, Shi GL, Zhuang YY, Zhu T (2005) Occurrence and distribution of polycyclic aromatic hydrocarbons in reclaimed water and surface water of Tianjin, China. J Hazard Mater 122:51-59

Chen Y, Lin T, Tang J, Xie Z, Tian C, Li J, Zhang G (2016) Exchange of polycyclic aromatic hydrocarbons across the air-water interface in the Bohai and yellow seas. Atmos Environ 141:153-160

Deng G, Yang W, Zhou G, Li Y, Liu S (2014) Heavy metals and polycyclic aromatic hydrocarbons in sediments from the Shenzhen River, South China. Environ Sci Pollut Res 21:10594-10600

Doong RA, Lin YT (2004) Characterization and distribution of polycyclic aromatic hydrocarbon contaminations in surface sediment and water from Gao-Ping River, Taiwan. Water Res 38:1733-1744

Harrison RM, Smith DJT, Luhana L (1996) Source apportionment of atmospheric polycyclic aromatic hydrocarbons collected from an urban location in Birmingham, UK. Environ Sci Technol 30:825832

Hermes AL, Sikes EL (2016) Particulate organic matter higher concentrations, terrestrial sources and losses in bottom waters of the turbidity maximum, Delaware estuary, USA. Estuar Coastal Shelf Sci 180: 179-189

Heydebreck F, Tang J, Xie Z, Ebinghaus R (2015) Alternative and legacy perfluoroalkyl substances: differences between European and Chinese River/estuary systems (vol 49, pg 8386, 2015). Environ Scie Technol 49:14742-14743

Hu N, Shi X, Liu J, Huang P, Liu Y, Liu Y (2010) Concentrations and possible sources of PAHs in sediments from Bohai Bay and adjacent shelf. Environ Earth Sci 60:1771-1782

Jiang T, Skyllberg U, Bjorn E, Green NW, Tang J, Wang D, Gao J, Li C (2017) Characteristics of dissolved organic matter (DOM) and relationship with dissolved mercury in Xiaoqing River-Laizhou Bay estuary, Bohai Sea, China. Environ Pollut 223:19-30

Keshavarzifard M, Zakaria MP, Hwai TS, Yusuff FM, Mustafa S, Vaezzadeh V, Magam SM, Masood N, Alkhadher SA, AbootalebiJahromi F (2014) Baseline distributions and sources of polycyclic aromatic hydrocarbons (PAHs) in the surface sediments from the Prai and Malacca Rivers, Peninsular Malaysia. Mar Pollut Bull 88: $366-372$

Khalili NR, Scheff PA, Holsen TM (1995) PAH source fingerprints for coke ovens, diesel and gasoline-engines, highway tunnels, and wood combustion emissions. Atmos Environ 29:533-542
Lau EV, Gan S, Ng HK, Poh PE (2014) Extraction agents for the removal of polycyclic aromatic hydrocarbons (PAHs) from soil in soil washing technologies. Environ Pollut 184:640-649

Li P, Xue R, Wang Y, Zhang R, Zhang G (2015a) Influence of anthropogenic activities on PAHs in sediments in a significant gulf of lowlatitude developing regions, the Beibu gulf, South China Sea: distribution, sources, inventory and probability risk. Mar Pollut Bull 90: $218-226$

Li Y, Li P, Ma W, Song Q, Zhou H, Han Q, Diao X (2015b) Spatial and temporal distribution and risk assessment of polycyclic aromatic hydrocarbons in surface seawater from the Haikou Bay, China. Mar Pollut Bull 92:244-251

Liu F, Liu J, Chen Q, Wang B, Cao Z (2013a) Pollution characteristics and ecological risk of polycyclic aromatic hydrocarbons (PAHs) in surface sediments of the southern part of the Haihe River system in China. Chin Sci Bull 58:3348-3356

Liu Y, Beckingham B, Ruegner H, Li Z, Ma L, Schwientek M, Xie H, Zhao J, Grathwohl P (2013b) Comparison of sedimentary PAHs in the rivers of Ammer (Germany) and Liangtan (China): differences between early- and newly-industrialized countries. Environ Sci Technol 47:701-709

Long ER, Ingersoll CG, Macdonald DD (2006) Calculation and uses of mean sediment quality guideline quotients: a critical review. Environ Sci Technol 40:1726-1736

Luo X-J, Chen S-J, Mai B-X, Sheng G-Y, Fu J-M, Zeng EY (2008) Distribution, source apportionment, and transport of PAHs in sediments from the Pearl River Delta and the northern South China Sea. Arch Environ Contam Toxicol 55:11-20

MacDonald DD, Ingersoll CG, Berger TA (2000) Development and evaluation of consensus-based sediment quality guidelines for freshwater ecosystems. Arch Environ Contam Toxicol 39:20-31

Mai BX, Qi SH, Zeng EY, Yang QS, Zhang G, Fu JM, Sheng GY, Peng PN, Wang ZS (2003) Distribution of polycyclic aromatic hydrocarbons in the coastal region off Macao, China: assessment of input sources and transport pathways using compositional analysis. Environ Sci Technol 37:4855-4863

Malik A, Verma P, Singh AK, Singh KP (2011) Distribution of polycyclic aromatic hydrocarbons in water and bed sediments of the Gomti River, India. Environ Monit Assess 172:529-545

Man YB, Kang Y, Wang HS, Lau W, Li H, Sun XL, Giesy JP, Chow KL, Wong MH (2013) Cancer risk assessments of Hong Kong soils contaminated by polycyclic aromatic hydrocarbons. J Hazard Mater 261:770-776

Meyer T, Lei YD, Wania F (2011) Transport of polycyclic aromatic hydrocarbons and pesticides during snowmelt within an urban watershed. Water Res 45:1147-1156

Nagy AS, Simon G, Szabo J, Vass I (2013) Polycyclic aromatic hydrocarbons in surface water and bed sediments of the Hungarian upper section of the Danube River. Environ Monit Assess 185:4619-4631

Pan X, Tang J, Li J, Guo Z, Zhang G (2010) Levels and distributions of PBDEs and PCBs in sediments of the Bohai Sea, North China. J Environ Monit 12:1234-1241

Parinos C, Gogou A, Bouloubassi I, Stavrakakis S, Plakidi E, Hatzianestis I (2013) Sources and downward fluxes of polycyclic aromatic hydrocarbons in the open southwestern Black Sea. Org Geochem 57:65-75

Qian X, Liang B, Liu X, Liu X, Wang J, Liu F, Cui B (2017) Distribution, sources, and ecological risk assessment of polycyclic aromatic hydrocarbons in surface sediments from the Haihe River, a typical polluted urban river in northern China. Environ Sci Pollut Res 24: 17153-17165

Qiao M, Wang CX, Huang SB, Wang DH, Wang ZJ (2006) Composition, sources, and potential toxicological significance of PAHs in the surface sediments of the Meiliang Bay, Taihu Lake, China. Environ Int 32:28-33 
Retnam A, Zakaria MP, Juahir H, Aris AZ, Zali MA, Kasim MF (2013) Chemometric techniques in distribution, characterisation and source apportionment of polycyclic aromatic hydrocarbons (PAHS) in aquaculture sediments in Malaysia. Mar Pollut Bull 69:55-66

Simcik MF, Eisenreich SJ, Lioy PJ (1999) Source apportionment and source/sink relationships of PAHs in the coastal atmosphere of Chicago and Lake Michigan. Atmos Environ 33:5071-5079

Steinhauer MS, Boehm PD (1992) The composition and distribution of saturated and aromatic-hydrocarbons in nearshore sediments, river sediments, and coastal peat of the ALASKAN BEAUFORT Sea implications for detecting anthropogenic hydrocarbon inputs. Mar Environ Res 33:223-253

Taupp T, Hellmann C, Gergs R, Winkelmann C, Wetzel MA (2017) Life under exceptional conditions-isotopic niches of benthic invertebrates in the estuarine maximum turbidity zone. Estuar Coasts 40: $502-512$

Tian Y-Z, Li W-H, Shi G-L, Feng Y-C, Wang Y-Q (2013) Relationships between PAHs and PCBs, and quantitative source apportionment of PAHs toxicity in sediments from Fenhe reservoir and watershed. J Hazard Mater 248:89-96

Tong R, Yang X, Su H, Pan Y, Zhang Q, Wang J, Long M (2017) Levels, sources and probabilistic health risks of polycyclic aromatic hydrocarbons in the agricultural soils from sites neighboring suburban industries in Shanghai. Sci Total Environ

Wang X-T, Miao Y, Zhang Y, Li Y-C, Wu M-H, Yu G (2013) Polycyclic aromatic hydrocarbons (PAHs) in urban soils of the megacity Shanghai: occurrence, source apportionment and potential human health risk. Sci Total Environ 447:80-89

Wang X, Xu H, Zhou Y, Wu C, Kanchanopas-Barnette P (2015) Distribution and source apportionment of polycyclic aromatic hydrocarbons in surface sediments from Zhoushan archipelago and Xiangshan Harbor, East China Sea. Mar Pollut Bull 101:895-902

Witt G, Leipe T, Emeis KC (2001) Using fluffy layer material to study the fate of particle-bound organic pollutants in the southern Baltic Sea. Environ Sci Technol 35:1567-1573

Ya M, Wang X, Wu Y, Li Y, Yan J, Fang C, Zhao Y, Qian R, Lin X (2017) Seasonal variation of terrigenous polycyclic aromatic hydrocarbons along the marginal seas of China: input, phase partitioning, and ocean-current transport. Environ Sci Technol 51:9072-9079
Yang D, Qi S, Zhang Y, Xing X, Liu H, Qu C, Liu J, Li F (2013) Levels, sources and potential risks of polycyclic aromatic hydrocarbons (PAHs) in multimedia environment along the Jinjiang River mainstream to Quanzhou Bay, China. Mar Pollut Bull 76:298-306

Yuan H, Zhang E, Lin Q, Wang R, Liu E (2016) Sources appointment and ecological risk assessment of polycyclic aromatic hydrocarbons (PAHs) in sediments of Erhai Lake, a low-latitude and highaltitude lake in Southwest China. Environ Sci Pollut Res 23:4430 4441

Yunker MB, Macdonald RW, Vingarzan R, Mitchell RH, Goyette D, Sylvestre S (2002) PAHs in the Fraser River basin: a critical appraisal of PAH ratios as indicators of PAH source and composition. Org Geochem 33:489-515

Zakaria MP, Takada H, Tsutsumi S, Ohno K, Yamada J, Kouno E, Kumata H (2002) Distribution of polycyclic aromatic hydrocarbons (PAHs) in rivers and estuaries in Malaysia: a widespread input of petrogenic PAHs. Environ Sci Technol 36:1907-1918

Zeng Q, Jeppesen E, Gu X, Mao Z, Chen H (2018) Distribution, fate and risk assessment of PAHs in water and sediments from an aquaculture- and shipping-impacted subtropical lake, China. Chemosphere 201:612-620

Zhang J, Liu G, Wang R, Huang H (2017) Polycyclic aromatic hydrocarbons in the water-SPM-sediment system from the middle reaches of Huai River, China: distribution, partitioning, origin tracing and ecological risk assessment. Environ Pollut 230:61-71

Zhao X, Ding J, You H (2014) Spatial distribution and temporal trends of polycyclic aromatic hydrocarbons (PAHs) in water and sediment from Songhua River, China. Environ Geochem Health 36:131-143

Zhen X, Tang J, Liu L, Wang X, Li Y, Xie Z (2018) From headwaters to estuary: distribution and fate of halogenated flame retardants (HFRs) in a river basin near the largest HFR manufacturing base in China. Sci Total Environ 621:1370-1377

Zhou JL, Fileman TW, Evans S, Donkin P, Llewellyn C, Readman JW, Mantoura RFC, Rowland SJ (1998) Fluoranthene and pyrene in the suspended particulate matter and surface sediments of the Humber estuary, UK. Mar Pollut Bull 36:587-597

Zong H, Ma X, Na G, Huo C, Yuan X, Zhang Z (2014) Polycyclic aromatic hydrocarbons (PAHs) in the mariculture zones of China's northern Yellow Sea. Mar Pollut Bull 85:172-178 